\title{
Cell Therapy for Critical Limb Ischemia: Advantages, Limitations, and New Perspectives for Treatment of Patients with Critical Diabetic Vasculopathy
}

\author{
Y. Gu ${ }^{1} \cdot$ A. Rampin ${ }^{2} \cdot$ V. V. Alvino ${ }^{1} \cdot$ G. Spinetti $^{2} \cdot$ P. Madeddu ${ }^{1}$ \\ Accepted: 13 January 2021 / Published online: 2 March 2021 \\ (C) The Author(s) 2021
}

\begin{abstract}
Purpose of Review To provide a highlight of the current state of cell therapy for the treatment of critical limb ischemia in patients with diabetes.

Recent Findings The global incidence of diabetes is constantly growing with consequent challenges for healthcare systems worldwide. In the UK only, NHS costs attributed to diabetic complications, such as peripheral vascular disease, amputation, blindness, renal failure, and stroke, average $£ 10$ billion each year, with cost pressure being estimated to get worse. Although giant leaps forward have been registered in the scope of early diagnosis and optimal glycaemic control, an effective treatment for critical limb ischemia is still lacking. The present review aims to provide an update of the ongoing work in the field of regenerative medicine. Recent advancements but also limitations imposed by diabetes on the potential of the approach are addressed. In particular, the review focuses on the perturbation of non-coding RNA networks in progenitor cells and the possibility of using emerging knowledge on molecular mechanisms to design refined protocols for personalized therapy.

Summary The field of cell therapy showed rapid progress but has limitations. Significant advances are foreseen in the upcoming years thanks to a better understanding of molecular bottlenecks associated with the metabolic disorders.
\end{abstract}

Keywords Critical Limb Ischemia · Diabetes Mellitus · MicroRNAs · Microvesicles · Proangiogenic cells · Vascular Stem and Progenitor cells

\section{Introduction}

Type 2 diabetes (T2D) and its complications have become one of the biggest threats to global health and economy [1]. Approximately $9 \%$ of adults in the UK were affected by diabetes in 2015 and $90 \%$ of them were diagnosed with T2D [2].

This article is part of the Topical Collection on Immunology, Transplantation, and Regenerative Medicine

Y. Gu and A. Rampin contributed equally to this work.

P. Madeddu

mdprm@bristol.ac.uk

1 Bristol Medical School, Translational Health Sciences, University of Bristol, Upper Maudlin Street, Bristol BS2 8HW, UK

2 Laboratory of Cardiovascular Research, IRCCS, MultiMedica, Milan, Italy
Endothelial dysfunction (ED) is acknowledged as a central player in diabetic vascular complications, including retinopathy, cardiomyopathy, renal failure, and diabetic foot [3]. The evolution of diabetes-related peripheral vascular disease (PVD) has been described at the cellular and tissue level. Insulin resistance and glucose level instability/ hyperglycaemia are key causative factors in the onset of microvascular ED and microangiopathy, which worsens the ischemic effects of concurrent atherosclerotic macroangiopathy. This detrimental combination results in progressive deterioration of tissue perfusion ultimately leading to critical limb ischemia (CLI) [4, 5].

CLI is defined as a clinical syndrome of chronic ischemic pain, skin ulcerations, and eventually gangrene, and it is associated with a highly increased mortality risk. Current treatments encompass pharmacological therapy and revascularization. However, a significant number of CLI patients are ineligible to reperfusion treatments because of the anatomic location of the 
lesions, the extent of the disease, and comorbidities. Such "no option CLI" (NO-CLI) patients often require limb amputation as an extreme life-saving procedure [6, 7]. However, the prognosis remains poor; diabetes-related amputations have a high risk of mortality, with a 5-year survival rate of $40-48 \%$.

In the last 20 years, regenerative medicine treatments have been proposed to address the unmet clinical needs of CLI patients. Chronologically, gene therapy using growth factors (GFs) was first introduced with the objective of fuelling reparative angiogenesis in affected muscles. The approach has shown some encouraging results, but continues to bear important limitations, which were mainly attributed to the poor gene transfer yield and limited duration of the effect, as well the inability of a single growth factor to resolve the pathogenic complexity of underlying molecular mechanisms [8-10]. More recently, the attention has shifted on micro-RNAs (miRNAs). Several short non-coding RNA (ncRNA) sequences reportedly contribute to the pathogenesis and progression of CLI through modulation of several downstream genes [11-13]. Moreover, miRNAs form functional clusters, which cooperate but also interfere with each other in different pathophysiological conditions. Hence, great interest has been focused on miRNA therapeutics and on miRNA regulating drugs [14-16]. Other categories of ncRNAs, including long ncRNA (lncRNAs) and circular RNAs (circRNA), are emerging as key players in diabetes cardiovascular complications $[17,18]$. Finally, cell therapy has also been employed as a regenerative treatment, with a growing number of clinical trials exploring the potential in ischemic disease and CLI [7]. The benefit of injecting cells in ischemic tissues is mainly attributed to the regulated release of growth factors, cytokines, and genetic material, either in soluble or vesicle-embedded form. Therefore, cell therapy represents a more global method to address the pathophysiological aspects of vascular disease.

This review highlights the current state of cell therapy for the treatment of CLI. First, we provide some examples of studies using different cell types; second, we indicate how T2D can influence the cell phenotype and behaviour, potentially limiting the benefits or causing undesired effects; and third, we will discuss the contribution of ncRNAs in the positive and adverse responses to the cell-based therapies. Our perspective is that, in the near future, the fields of cell therapy, gene therapy, and ncRNA therapy may advantageously converge into an all-inclusive approach capable of improving the quality of life and outcome of patients suffering from ischemic complications of diabetes.

\section{Cell Therapy for Vascular Regeneration in Critical Limb Ischemia}

Recent meta-analyses conducted on a multitude of clinical trials suggest that autologous stem cell-based therapies can actually improve the clinical outcome of diabetes-related CLI patients [19, 20]. However, some level of inconsistency has emerged; highlighting the need for further studies to better define all the critical aspects of the therapeutic protocol, including the source of the optimal cell type, the identification and screening for predictors of efficacy, as well as the administration modalities such as injection sites and treatment frequency. Table 1 illustrates examples of candidate cell types, classified according to the tissue source.

In the next sections, we summarize the latest results in the quest for a suitable cell therapy approach for NO-CLI. Clinically relevant developments in the field have been assessed by conducting a PubMed search of articles published in the last 5 years, extending then to essential prior publications that have led to current state of the art. In particular, we have revised the available evidence on mesenchymal stromal cells, mononuclear cells, and resident vascular progenitor cells.

\section{Mesenchymal Stromal Cells}

Mesenchymal stromal cells (MSCs) represent the leading cell type used in regenerative therapies for the treatment of autoimmune, inflammatory, and vascular diseases. MSCs secrete a wide variety of pro-inflammatory and anti-inflammatory cytokines, GFs, and prostaglandins under resting and inflammatory conditions $[21,22,35,36]$. These molecules are associated with immunomodulation, anti-apoptosis, angiogenesis, cell growth and differentiation, as well as anti-fibrosis and chemo-attraction [22, 37]. MSCs are currently considered among the most promising cell types as a regenerative option to the surgical treatment of CLI, as they provide some peculiar advantages [38]. Additionally, they reportedly express low levels of mayor histocompatibility complex (MHC) class II molecule, allowing for their use in allogenic treatments that would overcome specific functional limitations typical of T2D [39]. MSCs of different origins have been pursued as candidate cell types for cell therapy of NO-CLI patients [40•], with ongoing clinical trials mainly focusing on bone marrowderived MSCs (BM-MSCs).

CHAMP (Clinical and Histologic Analysis of Mesenchymal stromal cells in amPutations, trial number: NCT02685098) is an open label, single centre, nonrandomized phase I clinical trial started in September 2017 and due to be completed by the year 2025 . The study plans to enrol 16 patients requiring semi-elective lower extremity major amputation and aims to verify the safety and efficiency of concentrated BM aspirate (cBMA) and BM-MSCs intramuscular injection to NO-CLI patients [38]. This study was set up to better understand the mechanisms involved in a previous phase I study showing that intramuscular administration of MSCs-containing cBMA resulted in a 1- and 5-year amputation-free survival (AFS) rate of 86 and $74 \%$ respectively, a 
Table 1 Human stem and progenitor cell sources and types. Table source adapted in modified version from Hmadcha et al [21], and Soria-Juan et al [22]. $A F$, amniotic fluid; $A F-M S C s$, amniotic fluidderived mesenchymal stem cells; $A T$, adipose tissue; $A T-M S C s$, adipose tissue-derived mesenchymal stem cells; $B M$, bone marrow; $B M-M S C s$, bone marrow-derived mesenchymal stem cells; $B M-M N C s$, bone marrow-derived mononuclear cells; EPCs, endothelial progenitor cells;
$H S C s$, haematopoietic stem cells; $P B$, peripheral blood; $P B-M S C s$, peripheral blood-derived mesenchymal stem cells; $P B-M N C s$, peripheral blood-derived mononuclear cells; PL, placenta; $P L-M S C s$, placenta-derived mesenchymal stem cells; $U C$, umbilical cord; $U C$ MSCs, umbilical cord-derived mesenchymal stem cells; WJ, Wharton's jelly; WJ-MSCs, Wharton's jelly-derived mesenchymal stem cells

\begin{tabular}{lll}
\hline Sources & Tissue & Stem and progenitor cells \\
\hline Adult tissues & BM & HSCs, EPCs, BM-MNCs [23, 24] \\
& PB & PB-MNCs [25] \\
& BM stroma & BM-MSCs [26] \\
& PB stroma & PB-MSC [27] \\
AT & AT-MSCs [28] \\
Extraembryonic/neonatal tissues & cartilage, oral cavity, dental pulp, etc. & MSCs and pericytes [29, 30] \\
& UC & UC-MSCs [31] \\
& WJ & WJ-MSCs [32] \\
& AF & AF-MSCs [33] \\
\hline
\end{tabular}

result comparable to that achieved through revascularization [41]. Another endpoint of the trial is to determine the safety and efficacy at 6 months after injection, but also to inquire the short-term engraftment of BM-MSCs, their remodelling and paracrine activities after injection.

SAIL (allogeneic mesenchymal stromal cells for angiogenesis and neovascularization in no-option ischemic limbs, trial number: NCT03042572) is a randomized, double-blind, placebo-controlled clinical trial begun in 2018 and expected to end by July 2021. It will provide additional data on the safety and potential efficacy of allogeneic BM-MScs treatment for NO-CLI [42].

\section{Mononuclear Cells}

Following the isolation of $\mathrm{CD}^{+} 4^{+}$angiogenic mononuclear cells (MNCs) in 1997, a large number of studies have been dedicated to the evaluation of efficacy and safety as angiogenic cell therapy for NO-CLI patients [43••]. In a pioneering study, Tateyshi and colleagues demonstrated that intramuscular administration of BM-MNCs improved transcutaneous oxygen pressure (TcPO2), rest pain, and walking distance after 4-week and 6-month-follow ups compared to peripheral blood-derived MNCs (PB-MNCs), which were used a cellular control [44]. Several other studies reported a beneficial effect of autologous BM-MNCs and cBMA on AFS rate, amputation, pain, quality of life, Rutherford classification, and ankle brachial index (ABI) [45-47]. The benefit was attributed to the support of neovascularization within the ischemic tissues $[35,48 \cdot$, via direct engraftment, differentiation into appropriate tissue cells, and paracrine interaction with and stimulation of resident vascular cells [49]. A novel paracrine mechanism has been recently described for BM-MNCs, involving downregulation of the endogenous nitric oxide synthase (NOS)inhibitor asymmetric dymetylalanine [50].

Both BM-MNCs and PB-MNCs are still under preclinical and clinical investigation [51-54]. The derivation of MNCs from $\mathrm{PB}$ is attractive considering the procedural risk associated with BM extraction [55]. Nonetheless, different clinical trials reported contradictory outcomes with regard to the improvement of $\mathrm{ABI}$, ulcer healing, pain-free walking time, and limb salvage following the infusion of MNCs in CLI patients $[22,24,25,35,37]$. The reason for such variability might reside in the heterogeneous nature of MNCs. Therefore, experts in the field have moved to the evaluation of better defined MNC sub-populations, such as $\mathrm{CD}_{3} 4^{+}$and $\mathrm{CD}_{133^{+}}$MNCs. The latest meta-analysis conducted on clinical trials involving $\mathrm{CD} 34^{+} \mathrm{MNCs}$ indicates these cells can effectively reduce the rate of major amputation, while improving ulcer healing parameters [56]. Another concept emerging from meta-analysis is that the response to $\mathrm{CD} 34^{+} \mathrm{MNCs}$ may be dose-dependent. In support to this hypothesis, treatment of NO-CLI with GCS-Fmobilized- or enriched $\mathrm{CD} 34^{+} \mathrm{MNCs}$ displayed encouraging results [51, 57, 58]. Regarding mechanisms, previous studies on $\mathrm{CD}^{+} 4^{+} \mathrm{MNCs}$ showed that they can improve limb reperfusion through extracellular vesicle (EV)-mediated delivery of angiogenic miRNAs [22, 48•, 59, 60•]. In a diabetic mice model of CLI, the use of conditioned media collected from human $\mathrm{CD}_{133^{+}}$subset of $\mathrm{CD} 34^{+} \mathrm{MNCs}$ accelerated wound closure and reparative angiogenesis through paracrine signalling [61•]. Accordingly, a smallsized clinical study on the $\mathrm{CD} 133^{+}$subset of granulocytes colony-stimulating factor (GCS-F)-mobilized $\mathrm{CD}^{+} 4^{+} \mathrm{PB}-$ 
MNCs also provided encouraging results (75\% general improvement, $62.5 \%$ complete wound healing) [62].

Recent data on the application of specific MNCs subpopulations to NO-CLI treatment are therefore promising. Future studies will necessarily benefit from the deeper knowledge of the molecular mechanisms specific to T2D-related CLI.

\section{Resident Vascular Progenitor Cells}

Damage and pauperization of vascular cells, namely endothelial cells (ECs), vascular smooth muscle cells (VSMCs), and pericytes, represent a hallmark of microangiopathy. Therefore, supplying a boost of vascular progenitor cells to the site of ischemic injury, as a method of therapeutic vasculogenesis, could alleviate local quantitative and qualitative deficits and promote tissue reperfusion and repair.

Pericytes represent a viable source for such an endeavour, due to their key role in supporting a stable vascularization and in acting as the interface between vasculogenesis and myogenesis [63••]. Recent evidence indicates in fact that pericytes not only play a role in vascular reparative processes, but also in regeneration of myocytes together with satellite cells [63・•]. Preclinical evidence suggests that transplantation of pericytes could exert positive effects in different pathologies, including myopathies and ischemic disease [64••, 65-67]. The use of pericytes as a cell source for the treatment of NO-CLI is only recently beginning to gather attention. Our group has provided compelling preclinical evidence of efficacy and safety in murine models $[29,61,68 \bullet, 69,70]$. Nonetheless, autologous pericytes may be affected by underpinning pathology, as observed in T2D. We reported that pericytes from limb muscles of patients with diabetic vasculopathy display elevated levels of oxidative stress causing a dysfunctional phenotype [64••]. In T2D mice, treatment with dimethyl-2-oxoglutarate (DM-2OG), a tricarboxylic acid cycle metabolite with antioxidant properties, could restore pericyte redox balance and mitochondrial function, while concurrently allowing for enhanced pericyte-endothelial crosstalk [71•]. These results suggest that metabolic therapy may help to prevent or slow down vasculopathy in skeletal muscles of people with diabetes. Alternatively, allogeneic approaches could be considered. A study conducted in mice of induced limb ischemia showed an improvement in blood flow and collateral artery diameter recovery in animals treated with allogeneic pericytes [72].

Regarding other vascular cells, a recent small-size phase $\mathrm{Ib}$ clinical trial evaluated the efficiency of a 1:1 formulation containing ECs genetically modified to constitutively express angiopoietin-1 (ANG1) and VSMCs transfected with a vascular endothelial growth factor (VEGF) retroviral vector for the treatment of NO-CLI. Some improvements were observed. One-year amputation-free survival rate was $72 \%$ (13/18) for Rutherford 4 and 5 patients, whereas all 5 patients with
Rutherford 6 underwent amputation. Of the 12 with nonhealing ulcers, 6 had complete healing and 2 others had a significant reduction $(>66 \%)$ in ulcer size. Outcomes did not associate with dose stratification. No severe adverse events were observed related to the therapy [73].

Another promising approach that is expected to reach the clinical trial stage soon involves the application of humaninduced pluripotent stem cells- (hiPSCs) or SCs-derived EC products [74-77]. Evidence of efficacy was provided by a recent preclinical study that reported an accelerated reperfusion and increased capillary density in CLI mice treated with a clinical grade hSCs-derived EC product [78]. Interestingly, such product was composed of a heterogeneous cell population, enriched in CD144 and CD31-positive-differentiated ECs, but also expressing mesenchymal and pericyte markers, thus indicating both ECs and pericytes could participate in the therapeutic effect. Altogether, these studies suggest that combinations of specialized vascular cells may be optimally suited to regenerate the vasculature of NO-CLI patients.

\section{Diabetes-Related Limitations}

The harsh tissue environment created by the combination of diabetes and ischemia can hamper the functionality of candidate cell products for autologous and, potentially, allogeneic treatments (Fig. 1). The following sections summarize relevant molecular targets to improve cell therapy outcomes in patients with T2D.

\section{Molecular Alterations in Ischemic Tissue and Circulating and Bone Marrow Resident Progenitor Cells}

T2D is associated with increased levels of mitochondrial and endoplasmic reticulum (ER) oxidative stress, resulting from hyperglycaemia-induced activation of the electron transfer chain (ETC) in the mitochondria [79]. Consequently, large amounts of reactive oxygen species (ROS) are produced and diffused to the ER through the mitochondria-associated membranes (MAMs).

An impairment of the protein-folding machinery triggers autophagy, an important pathway that allows cells to dispose of the ROS-damaged macromolecules. However, autophagy is inhibited by insulin through the activation of mammalian target of rapamycin (mTOR), which results in unc-51 like autophagy activating kinase 1 (ULK1) inactivation under insulin resistance conditions [80]. In line with this, recent evidence reports an inhibition of mitophagy (mitochondriaspecific autophagy) in PB-MNCs from patients with T2D [81]. Moreover, tumour suppressor-programmed cell death-4 (PDCD4) overexpression was demonstrated in diabetic PBMNCs [82•]. These results mirror the recent observation that 


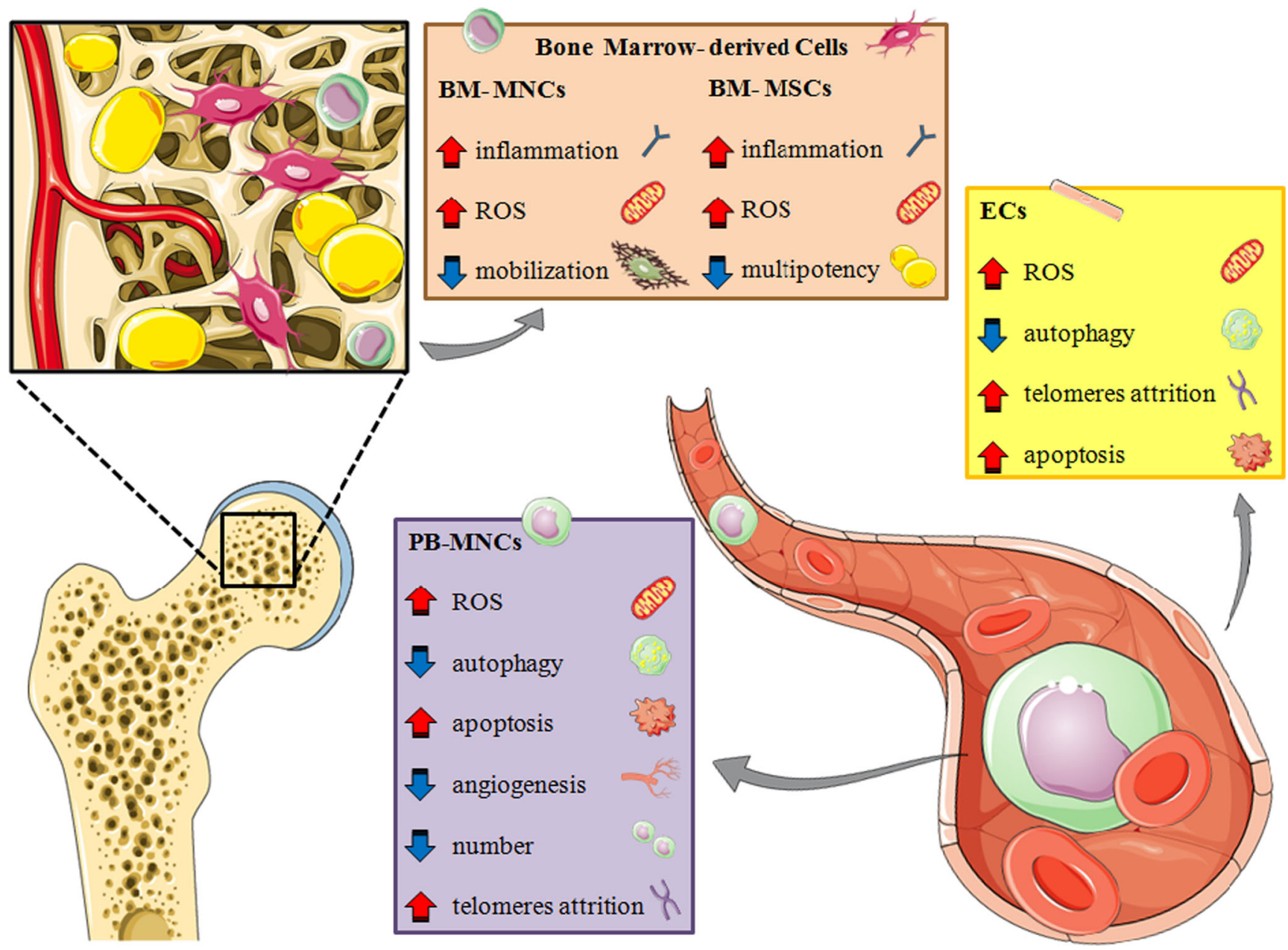

Fig. 1 Damaging effect of diabetes on stem/progenitor cells in bone marrow and peripheral circulation. BM bone marrow, MNCs mononuclear cells, MSCs mesenchymal stromal cells, ECs endothelial cells, PB peripheral blood. This figure was created using images from

the inhibition of autophagy associates with an increased expression of $P D C D 4$ in a human cancer cell line [83].

Importantly, hyperglycaemia-induced accumulation of advanced glycation end-products (AGEs) and ROS production concurrently results in endothelial nitric oxide synthase (eNOS) dimer uncoupling, which leads to the accumulation of highly reactive nitrogen species [84-86]. This, in turn, affects the mobilization and function of BM-derived progenitors, which are thought to have pro-angiogenic and healing potential. Selective inhibition of the PI3K/Akt signalling pathway during insulin resistance can contribute to eNOS-reduced expression and function, thereby expanding the effect of diabetes on NO equilibrium [87, 88]. Excess ROS production accelerates telomere length shortening, or telomeres attrition, a process that is exacerbated in T2D. Telomeres attrition is significantly higher in ECs and PB-MNCs from patients with T2D, and is associated with faster vascular ageing [89].

Patients with T2D exhibit decreased circulating CD34 ${ }^{+}$ MNCs, a deficit that predicts the risk of complications and
Servier Medical Art Commons Attribution 3.0 Unported License. (http:// smart.servier.com). Servier Medical Art by Servier is licensed under a Creative Commons Attribution 3.0 Unported License

death [90, 91, 92••, 93, 94]. Various mobilizing mechanisms contributing to the liberation of BM-resident progenitor cells in the circulation are profoundly altered in T2D, a defect known as mobilopathy or myelokathexis, with negative consequences for physiologic hematopoiesis, immune regulation, and tissue regeneration, as reviewed in [95]. Nociceptive perception is depressed in CLI patients favouring the formation of foot ulcers. Interestingly, depression of nociceptive reflexes can also contribute to mobilopathy in mice and patients with complicated T2D, reducing the recruitment of reparative cells that express the nociceptive receptors $[96,97]$.

In addition to causing an altered progenitor cell mobilization, T2D was shown to drastically alter the cellular composition of BM in favour of adipose tissue accumulation; this transformation can hinder the intrinsic regenerative potential of resident mesenchymal and hematopoietic cells and compromise their utility for therapeutic transplantation purposes [98]. Moreover, our group has discovered that the in vitro migratory activity of $\mathrm{CD} 34^{+} \mathrm{MNCs}$ positively correlated with 
cardiovascular death, independently from other predictive factors, such as age, coronary artery disease, serum C-reactive protein, and glomerular filtration rate [82•]. At a first glimpse, these findings may appear counterintuitive, considering that migration is instrumental to BM-derived cells to reach damaged tissues, unless these cells have turned into deleterious elements because of T2D. In line with this possibility, a pilot, phase IIa, double-blind, randomized, placebo-controlled trial (NCT02790957) conducted in patients with T2D with ischemic wounds showed that mobilization treatment with the CXCR4 antagonist plerixafor had negative effects on wound healing as compared to the placebo, leading to premature trial termination after a pre-planned interim analysis [99].

Equilibrium in the paracrine- and GAP junction-supported crosstalk between vascular mural cells is impaired in T2Drelated CLI. Evidence suggests that such damage includes permanent as well as transient epigenetic modifications that could hinder the efficacy of pericytes and ECs in autologous cell therapy $[72,100,101]$. Interestingly, the pericyte-EC crosstalk is also altered in BM, with depression of AKTdependent angiocrine signalling being a hallmark of local microangiopathy $[102,103]$. Transfection with the adenoviral vector carrying the coding sequence for constitutively active AKT rescued functional defects and angiocrine signalling in BM pericytes, suggesting this could be a molecular target to restore the progenitor cell niche [102]. Likewise, targeting inflammatory cytokines could improve BM function in T2D. Pharmacological inhibition of MCP-1 signalling reduced adiposity in $\mathrm{BM}$ of $\mathrm{T} 2 \mathrm{D}$ mice, restoring, at least in part, the balance between adipogenesis and hematopoiesis [104].

Taken together, these observations indicate that T2D significantly affects the functionality of virtually all the cell types currently considered as viable candidates for CLI cell therapy. Therefore, innovative techniques able to restore the functionality of the transplanted cells, as well as the development of reliable allogeneic alternatives, could represent valuable choices for future research.

\section{MicroRNAs in Diabetes-Related Vascular Disease: Implications for Cell Therapy}

The prolonged modification of the cellular epigenetic profile because of a metabolic insult is known as metabolic memory. Epigenetic modifications could significantly limit the efficacy of autologous cell therapy in CLI-T2D patients [105-108]. Importantly, miRNAs can affect the epigenetic mechanisms by targeting key enzymes involved in establishing epigenetic memory. For instance, T2D is associated with upregulation of pro-inflammatory miRNAs (e.g., miR-125b, mir-146a-5p, and miR-29a-3p) in aortic ECs, causing a chronic inflammatory status that closely resembles the senescence-activated secretory phenotype (SASP). Notably, this phenomenon is reversible, with miRNA inhibition being able to reverse NF-KB pathway activation in vascular cells [109]).

The miR-126 offers another relevant example of the miRNAs ability to modulate metabolic memory at different levels. Indeed, miR-126 can bind the 3'-UTR regions of, among others, insulin receptor substrate-1 (IRS-1), phosphatidyl inositol 3-phosphate kinase receptor-2 (PI3KR-2), sprouty related EVH1 domain-containing-1 (SPRED-1), and disintegrin and metalloproteinase domain-containing protein9 (ADAM-9). This multiple targeting respectively results in IR modulation, EC survival and proliferation, and modulation of cell migration [110-113]. In T2D, miR-126 is reportedly downregulated, possibly due to a compensatory response to insulin resistance, thereby contributing to ED and vascular disease [114]. In diabetic mice, restoration of miR-126 levels reduced PVD development $[14,113]$. MNCs isolated from PB of diabetic patients displayed a downregulation of miR-126, resulting in reduced proliferation and increased apoptosis through upregulation of its target Spred1; whereas, forced miR-126 expression improved efferocytosis in human macrophages [111].

Overexpression of circulating miR-15a and miR-16-1, which shares a common pre-pri-miRNA under the transcriptional control of E2F-1, is predictive of restenosis and limb amputation in T2D-CLI patients undergoing percutaneous angioplasty $[115 \bullet \cdot]$. In line with a negative influence of these microRNAs on cell therapy, transplantation of PB-MNCs ex vivo-engineered with anti-miR-15a/16 improved postischemic blood flow recovery and muscular arteriole density in immunodeficient mice [115••].

In vitro studies unravelled the role of hypoxia in the modulation of miR-532-5p and miR-210 in pericytes and MNCs, respectively $[12,116]$. Induction of miR-532-5p by hypoxia results in ANG1 downregulation and pericyte dysfunction. Whereas, in MNCs, induction of miR-210 by hypoxia leads to ephrin $\mathrm{A} 3$ downregulation eventually enhancing the $\mathrm{MNC}$ proangiogenic potential. Notably, ex vivo transfection of MNCs with miR-210 overexpressing vectors resulted in enhanced angiogenesis stimulation following transplantation in a mouse model of limb ischemia [12].

MiRNAs were also identified as important regulators of adipose tissue functions and may link inflammation and insulin resistance, as reviewed in [117]. Interestingly, some of these adipo-miRNAs are also expressed by vascular cells and implicated in T2D and ageing-associated vasculopaties [118].

These observations collectively point to miRNAs as pivotal players in the onset and progression of $\mathrm{T} 2 \mathrm{D}$ and CLI. Consequently, miRNAs represent viable targets for the development of therapeutic strategies including ex vivo expression level modification in candidate cell products. Table 2 provides a list of deregulated miRNAs in $\mathrm{T} 2 \mathrm{D}$ - related $\mathrm{ED} / \mathrm{CLI}$. 
Table 2 MiRNAs differently expressed in patients with $\mathrm{T} 2 \mathrm{D}$ affected by CLI or ED. EPCs, endothelial progenitor cells; HUVECs, human umbilical veinderived endothelial cells; miRNA, microRNA; $M N C s$, mononuclear cells; $P B$, peripheral blood

\begin{tabular}{|c|c|c|}
\hline miRNAs affected by ED/CLI in T2D & Up/downregulation & Sample type \\
\hline miR-15a & Up & PB-EPCs, serum $[115 \bullet \bullet]$ \\
\hline miR-16-1 & Up & PB-EPCs, serum $[115 \bullet \bullet]$ \\
\hline miR-130a & Down & EPCs [119] \\
\hline $\operatorname{miR}-126$ & Down & EPCs [111] \\
\hline miR-126-3p & Down & Plasma [120] \\
\hline miR-21 & Down & EPCs $[82 \bullet]$ \\
\hline $\operatorname{miR}-21-5 p$ & Up & Plasma [120] \\
\hline $\operatorname{miR}-200 b-3 p$ & Up & Plasma [121] \\
\hline $\operatorname{miR}-2115-3 p$ & Up & Plasma [121] \\
\hline $\operatorname{miR} 431-5 p$ & Up & Plasma [121] \\
\hline miR-486-5p & Up & Plasma [121] \\
\hline $\operatorname{miR}-210-3 p$ & $\mathrm{Up}$ & Plasma [121] \\
\hline miR-1264 & $\mathrm{Up}$ & Plasma [121] \\
\hline $\operatorname{miR} 323 b-5 p$ & $\mathrm{Up}$ & Plasma [121] \\
\hline $\operatorname{miR}-5579-3 p$ & Down & Plasma [121] \\
\hline miR-665 & Down & Plasma [121] \\
\hline miR-4285 & Down & Plasma [121] \\
\hline $\operatorname{miR}-500 a-3 p$ & Down & Plasma [121] \\
\hline miR-4739 & Up & Whole blood [122] \\
\hline miR-342-3p & $\mathrm{Up}$ & PB EPCs [123] \\
\hline miR-29 & Down & Arteriole biopsies [124] \\
\hline miR-149-5p & Down & HUVECs [125] \\
\hline $\operatorname{miR}-4463$ & Up & Femoral arteries, HUVECs [126] \\
\hline $\operatorname{miR}-423$ & Down & Plasma [127] \\
\hline $\operatorname{miR}-199 a-3 p$ & Down & PB [128] \\
\hline miR-93 & Up & Plasma [129] \\
\hline $\operatorname{miR}-23 \mathrm{c}$ & $\mathrm{Up}$ & PB-MNC, biopsies [130] \\
\hline $\operatorname{miR}-92 \mathrm{a}$ & $\mathrm{Up}$ & PB [131] \\
\hline
\end{tabular}

\section{Long Noncoding RNAs in Diabetes-Related Vascular Disease: Implications for Cell Therapy}

LncRNAs represent a class of transcribed RNA molecules that are longer than 200 nucleotides and yet do not encode proteins. Several lncRNAs participate in the regulation of stem cell properties including their potential for self-renewal and differentiation, which help in maintenance of normal cell and tissue homeostasis. We have recently reported a T2D-dependent mechanism involving miR-21 downregulation $\mathrm{CD} 34^{+} \mathrm{MNCs}$ and induction of its inhibitory target PDCD4, a tumor suppressor protein involved in programmed cell death [82•]. We also found that several lncRNAs that act as sponges for miR-21 were overexpressed in $\mathrm{CD}_{3} 4^{+} \mathrm{MNCs}$ and $\mathrm{PB}$ of patients with T2D. We proposed that this altered paracrine signalling may convey antiangiogenic and proapoptotic features from CD $34^{+}$ cells to the endothelium [82•]. The study has important implications for cell therapy, calling for caution in using $\mathrm{CD} 34^{+}$cells that carry a proapoptotic and antiangiogenic molecular signature, e.g., low miR-21/high PDCD4.
Several lncRNAs are gathering attention as theragnostic tools in vascular complications of T2D as reviewed in [132]. An example can be found in MALAT-1, which is one of the most studied lncRNAs expressed in ECs, where it regulates hyperglycaemia-induced inflammatory process [133]. Moreover, its knockdown was associated to an amelioration of ED [134]. Interestingly, MALAT-1 is also upregulated in $\mathrm{CD}_{3}{ }^{+}$cells from patients with T2D, suggesting a general implication in vascular dysfunction and cell-related repair processes [82•]. Another IncRNA, MEG-3, was associated with a protective effect towards high glucose (HG)-treated HUVECs [135].

Recent evidence suggests a role for circRNAs in diabetesrelated epigenetic regulation. CircRNAs represent a large class of stable RNAs produced by circularization of specific exons. In vivo, they are generated by the spliceosome via backsplicing and can modulate gene expression through sequestration of RNA-binding proteins, transcriptional regulation, or sequestration of their target miRNAs [136-138]. cPWWP2A is a circRNA overexpressed by retinal pericytes of streptozotocininduced diabetic mice. It can be delivered to ECs through EVs- 
mediated paracrine signalling, resulting in miR-579 sequestration and consecutive overexpression of ANG1, occludin, and sirtuin 1 , thereby providing a protective effect [139]. Likewise, HG condition triggers another protective mechanism involving the circRNA-0054633-mediated downregulation of miR-218, eventually contrasting $\mathrm{ED}[140]$. On the other hand, overexpression of circHIPK3 has a deleterious effect in diabetic retinopathy through sponging of miR-30a-3p [141]. Likewise, circRNA-ZNF609 silencing was shown to ameliorate ED in a diabetic mice model [142]. Another study showed that culturing HUVECs under HG conditions activates circ-0068087, a sponge circRNA responsible for the upregulation of NF- $\mathrm{KB}$-mediated inflammation through the downregulation of its target miR-197 [143].

Recent sequencing studies have advanced the understanding of diversity in non-coding RNAs due to T2D. In a high throughput RNA-sequencing study, the comparison between blood samples from three just-diagnosed patients with T2D and three healthy patients unravelled a multitude of differentially expressed miRNAs, IncRNAs, circRNAs as well as mRNAs [144]. Furthermore, another RNA-sequencing study comparing patients with diabetes with and without diabetic foot complications showed that 632 mRNAs and 33 circRNAs were differently expressed in the sera of the two groups [145].

Taken together, these results provide a plethora of potential molecular targets to improve the functionality of autologous cell therapy in the treatment of NO-CLI.

\section{Conclusions}

The quest for an alternative treatment to surgical amputation for NO-CLI patients relentlessly strives on, as reported in this short review, accompanied by the steadily expanding account of the molecular networks embedded in the pathological milieu. Several studies reported here highlighted the importance of stem and progenitor cells as well as ncRNAs in such context. The constantly growing acknowledgement of the molecular connections between CLI and T2D suggests novel therapeutic approaches will rise soon. We can therefore conclude that future trends in CLI cell therapy will keep on pursuing the refinement of the ideal strategy to achieve tissue reperfusion, TcPO2 increase, pain at rest reduction, as well as improvement of painless walking distance, AFS rate, and mortality rate. Additionally, miRNAs emerge as essential therapeutic and diagnostic targets as they are broadly involved in the mechanisms of neovascularization. The wide range of recently discovered angiogenic miRNAs associated with every known aspect of CLI pathophysiology is likely to provide a solid base to boost the sprouting of innovative strategies and refine current cell therapy techniques soon. The definition of reliable predictors of responsiveness to a given treatment should also enhance the efficacy of future cell therapy trials [146]. Finally, evidence reported in meta-analyses indicate that large, double-blind, placebo-controlled, randomized trials with long-term follow-up are mandatory to firmly establish cell therapy as an acceptable treatment of CLI.

Abbreviations ABI, Ankle-brachial index; AFS, Amputation-free survival; ANG, Angiotensin; ANG1, Angiopoietin 1; BM, Bone marrow; BM-MNCs, Bone marrow-derived mononuclear cells; CCL2, Chemokine C-C motif ligand 2; circRNAs, Circular RNAs; CLI, Critical limb ischaemia; cBMA, Concentrated bone marrow aspirate; CXCL12, C-X-C motif chemokine 12; CXCR4, C-X-C chemokine receptor type 4; ECs, Endothelial cells; ED, Endothelial dysfunction; eNOS, Endothelial nitric oxide synthase; EPCs, Endothelial progenitor cells; ETC, Electron transfer chain; EVs, Endothelial vescicles; FGF, Fibroblast growth factor; GFs, Growth factors; G-CSF, Granulocyte colony stimulating factor; HGF, Hepatocyte growth factor; hiPSCs, Humaninduced-pluripotent stem cells; HPSCs, Haematopoietic progenitor stem cells; HSCs, Haematopoietic stem cells; IGF-1, Insulin growth factor-1; IRS-1, Insulin receptor substrate-1; MAMs, Mitochondria-associated membranes; MHC, Mayor histocompatibility complex; mTOR, Mammalian target of rapamycin; miRNAs, Micro RNAs; MNCs, Mononuclear cells; MSCs, Mesenchymal stromal cells; lncRNA, Long non-coding RNA; ncRNA, Non-coding RNA; NO-CLI, No option CLI; $\mathrm{PB}$, Periphral blood; PB-MNCs, Peripheral blood-derived mononuclear cells; PDCD4, ProgrammeD cell death 4; PDGF, Platelet-derived growth factor; PVD, Peripheral vascular disease; ROS, Reactive oxidative species; SASP, Senescent activated secretory phenotype; T2D, Type 2 diabetes; TcPO2, Transcutaneous oxygen pressure; ULK1, Unc-51 like autophagy activating kinase 1; VEGF, Vascular endothelial growth factor; VSMC, Vascular smooth muscle cells

Funding Miss Yue Gu is recipient of a China-UK scholarship. The study was supported by the British Heart Foundation (BHF) project grants 'Targeting of protein kinase $\mathrm{C}$ beta II (PKC $\beta \mathrm{II})$ to improve vascular and muscular fitness in diabetic peripheral ischaemia' (PG/16/101/ 32622) and "A novel pericyte mechanism involving the transcriptional activator Nrf2 and the transcriptional repressor Bach1 modulates antioxidant defence response and angiopoietin-dependent vascular stabilisation during reparative angiogenesis" (PG/19/49/34440) both awarded to PM. The funder was not involved in the design of the study; the collection, analysis, and interpretation of data; writing the report; and did not impose any restrictions regarding the publication of the report.

\section{Declarations}

Human and Animal Rights and Informed Consent This article does not contain any studies with human or animal subjects performed by any of the authors.

Conflict of Interest The authors declare no competing interests.

Open Access This article is licensed under a Creative Commons Attribution 4.0 International License, which permits use, sharing, adaptation, distribution and reproduction in any medium or format, as long as you give appropriate credit to the original author(s) and the source, provide a link to the Creative Commons licence, and indicate if changes were made. The images or other third party material in this article are included in the article's Creative Commons licence, unless indicated otherwise in a credit line to the material. If material is not included in the article's Creative Commons licence and your intended use is not permitted by statutory regulation or exceeds the permitted use, you will need to obtain permission directly from the copyright holder. To view a copy of this licence, visit http://creativecommons.org/licenses/by/4.0/. 


\section{References}

Papers of particular interest, published recently, have been highlighted as:

- Of importance

- Of major importance

1. Zheng Y, Ley SH, Hu FB. Global aetiology and epidemiology of type 2 diabetes mellitus and its complications. Nat Rev Endocrinol. 2018;14(2):88-98.

2. Holman N, Young B, Gadsby R. Current prevalence of type 1 and type 2 diabetes in adults and children in the UK. Diabet Med. 2015;32(9):1119-20.

3. Kolluru GK, Bir SC, Kevil CG. Endothelial dysfunction and diabetes: effects on angiogenesis, vascular remodeling, and wound healing. Int J Vasc Med. 2012;2012:918267.

4. Caporali A, Pani E, Horrevoets AJ, Kraenkel N, Oikawa A, SalaNewby GB, et al. Neurotrophin p75 receptor (p75NTR) promotes endothelial cell apoptosis and inhibits angiogenesis: implications for diabetes-induced impaired neovascularization in ischemic limb muscles. Circ Res. 2008;103(2):e15-26.

5. Shi Y, Vanhoutte PM. Macro- and microvascular endothelial dysfunction in diabetes. J Diabetes. 2017;9(5):434-49.

6. Elsayed S, Clavijo LC. Critical limb ischemia. Cardiol Clin. 2015;33(1):37-47.

7. Davies MG. Critical limb ischemia: cell and molecular therapies for limb salvage. Methodist Debakey Cardiovasc J. 2012;8(4):20 7.

8. Isner JM, Pieczek A, Schainfeld R, Blair R, Haley L, Asahara T, et al. Clinical evidence of angiogenesis after arterial gene transfer of phVEGF165 in patient with ischaemic limb. Lancet. 1996;348(9024):370-4.

9. Ha XQ, Li YM, Bi JJ, Zhang QL, Wu ZZ. Plasmid pUDKH gene therapy of rat acute hindlimb ischemia: an experimental study. Zhonghua Yi Xue Za Zhi. 2003;83(17):1521-4.

10. Cui S, Guo L, Li X, Gu Y, Fu J, Dong L, et al. Clinical safety and preliminary efficacy of plasmid pUDK-HGF expressing human hepatocyte growth factor (HGF) in patients with critical limb ischemia. Eur J Vasc Endovasc Surg. 2015;50(4):494-501.

11. Hamburg NM, Leeper NJ. Therapeutic potential of modulating microRNA in peripheral artery disease. Curr Vasc Pharmacol. 2015;13(3):316-23.

12. Besnier M, Gasparino S, Vono R, Sangalli E, Facoetti A, Bollati $\mathrm{V}$, et al. miR-210 enhances the therapeutic potential of bonemarrow-derived circulating proangiogenic cells in the Setting of Limb Ischemia. Mol Ther. 2018;26(7):1694-705.

13. Perez-Cremades D, Cheng HS, Feinberg MW. Noncoding RNAs in critical limb ischemia. Arterioscler Thromb Vasc Biol. 2020;40(3):523-33.

14. Togliatto G, Trombetta A, Dentelli P, Gallo S, Rosso A, Cotogni $\mathrm{P}$, et al. Unacylated ghrelin induces oxidative stress resistance in a glucose intolerance and peripheral artery disease mouse model by restoring endothelial cell miR-126 expression. Diabetes. 2015;64(4):1370-82.

15. Neale JPH, Pearson JT, Katare R, Schwenke DO. Ghrelin, MicroRNAs, and critical limb ischemia: hungering for a novel treatment option. Front Endocrinol (Lausanne). 2017;8:350.

16. Granata R, Settanni F, Julien M, Nano R, Togliatto G, Trombetta A, et al. Des-acyl ghrelin fragments and analogues promote survival of pancreatic beta-cells and human pancreatic islets and prevent diabetes in streptozotocin-treated rats. J Med Chem. 2012;55(6):2585-96.
17. Bei Y, Yang T, Wang L, Holvoet P, Das S, Sluijter JPG, et al. Circular RNAs as potential theranostics in the cardiovascular system. Mol Ther Nucleic Acids. 2018;13:407-18.

18. Beltrami C, Angelini TG, Emanueli C. Noncoding RNAs in diabetes vascular complications. J Mol Cell Cardiol. 2015;89(Pt A): $42-50$.

19. Gao W, Chen D, Liu G, Ran X. Autologous stem cell therapy for peripheral arterial disease: a systematic review and meta-analysis of randomized controlled trials. Stem Cell Res Ther. 2019;10(1): 140.

20. Fadini GP, Agostini C, Avogaro A. Autologous stem cell therapy for peripheral arterial disease meta-analysis and systematic review of the literature. Atherosclerosis. 2010;209(1):10-7.

21. Hmadcha A, Dominguez-Bendala J, Wakeman J, Arredouani M, Soria B. The immune boundaries for stem cell based therapies: problems and prospective solutions. J Cell Mol Med. 2009;13(8A):1464-75.

22. Soria-Juan B, Escacena N, Capilla-Gonzalez V, Aguilera Y, Llanos L, Tejedo JR, et al. Cost-effective, safe, and personalized cell therapy for critical limb ischemia in type 2 diabetes mellitus. Front Immunol. 2019;10:1151.

23. Fadini GP, Losordo D, Dimmeler S. Critical reevaluation of endothelial progenitor cell phenotypes for therapeutic and diagnostic use. Circ Res. 2012;110(4):624-37.

24. Walter DH, Krankenberg H, Balzer JO, Kalka C, Baumgartner I, Schluter M, et al. Intraarterial administration of bone marrow mononuclear cells in patients with critical limb ischemia: a randomized-start, placebo-controlled pilot trial (PROVASA). Circ Cardiovasc Interv. 2011;4(1):26-37.

25. Huang P, Li S, Han M, Xiao Z, Yang R, Han ZC. Autologous transplantation of granulocyte colony-stimulating factor-mobilized peripheral blood mononuclear cells improves critical limb ischemia in diabetes. Diabetes Care. 2005;28(9):2155-60.

26. Gupta PK, Chullikana A, Parakh R, Desai S, Das A, Gottipamula $\mathrm{S}$, et al. A double blind randomized placebo controlled phase I/II study assessing the safety and efficacy of allogeneic bone marrow derived mesenchymal stem cell in critical limb ischemia. J Transl Med. 2013;11:143.

27. Xie B, Luo H, Zhang Y, Wang Q, Zhou C, Xu D. Autologous stem cell therapy in critical limb ischemia: a meta-analysis of randomized controlled trials. Stem Cells Int. 2018;2018:7528464.

28. Lian K, Wang Q, Zhao S, Yang M, Chen G, Chen Y, et al. Pretreatment of diabetic adipose-derived stem cells with mitoTEMPO reverses their defective proangiogenic function in diabetic mice with critical limb ischemia. Cell Transplant. 2019;28(12):1652-63.

29. Carrabba M, De Maria C, Oikawa A, Reni C, RodriguezArabaolaza I, Spencer H, et al. Design, fabrication and perivascular implantation of bioactive scaffolds engineered with human adventitial progenitor cells for stimulation of arteriogenesis in peripheral ischemia. Biofabrication. 2016;8(1): 015020 .

30. Munroe M, Dvoretskiy S, Lopez A, Leong J, Dyle MC, Kong H, et al. Pericyte transplantation improves skeletal muscle recovery following hindlimb immobilization. FASEB J. 2019;33(6):7694706.

31. Gao WH, Gao HY, Li YT, Huang PP. Effectiveness of umbilical cord mesenchymal stem cells in patients with critical limb ischemia. Med Clin (Barc). 2019;153(9):341-6.

32. Musial-Wysocka A, Kot M, Sulkowski M, Majka M. Regenerative potential of the product "CardioCell" derived from the Wharton's jelly mesenchymal stem cells for treating hindlimb ischemia. Int J Mol Sci. 2019;20(18):4632.

33. Mirabella T, Cilli M, Carlone S, Cancedda R, Gentili C. Amniotic liquid derived stem cells as reservoir of secreted angiogenic 
factors capable of stimulating neo-arteriogenesis in an ischemic model. Biomaterials. 2011;32(15):3689-99.

34. Liang L, Li Z, Ma T, Han Z, Du W, Geng J, et al. Transplantation of human placenta-derived mesenchymal stem cells alleviates critical limb ischemia in diabetic nude rats. Cell Transplant. 2017;26(1):45-61.

35. Qadura M, Terenzi DC, Verma S, Al-Omran M, Hess DA. Concise review: cell therapy for critical limb ischemia: an integrated review of preclinical and clinical studies. Stem Cells. 2018;36(2):161-71.

36. Hoogduijn MJ, Popp F, Verbeek R, Masoodi M, Nicolaou A, Baan $\mathrm{C}$, et al. The immunomodulatory properties of mesenchymal stem cells and their use for immunotherapy. Int Immunopharmacol. 2010;10(12):1496-500.

37. Wu Q, Chen B, Liang Z. Mesenchymal stem cells as a prospective therapy for the diabetic foot. Stem Cells Int. 2016;2016:4612167.

38. Wang SK, Green LA, Drucker NA, Motaganahalli RL, Fajardo A, Murphy MP. Rationale and design of the Clinical and Histologic Analysis of Mesenchymal Stromal Cells in AmPutations (CHAMP) trial investigating the therapeutic mechanism of mesenchymal stromal cells in the treatment of critical limb ischemia. $\mathrm{J}$ Vasc Surg. 2018;68(1):176-81 e1.

39. Ryan JM, Barry FP, Murphy JM, Mahon BP. Mesenchymal stem cells avoid allogeneic rejection. J Inflamm (Lond). 2005;2:8.

40. Cooke JP, Meng S. Vascular regeneration in peripheral artery disease. Arterioscler Thromb Vasc Biol. 2020;40(7):1627-34 Important. The article provides recent evidence on the multifaced approach to diagnose and treat critical limb ischemia.

41. Murphy MP, Lawson JH, Rapp BM, Dalsing MC, Klein J, Wilson MG, et al. Autologous bone marrow mononuclear cell therapy is safe and promotes amputation-free survival in patients with critical limb ischemia. J Vasc Surg. 2011;53(6):1565-74 e1.

42. Wijnand JGJ, Teraa M, Gremmels H, van Rhijn-Brouwer FCC, de Borst GJ, Verhaar MC. Rationale and design of the SAIL trial for intramuscular injection of allogeneic mesenchymal stromal cells in no-option critical limb ischemia. J Vasc Surg. 2018;67(2):65661.

43.•- Asahara T, Murohara T, Sullivan A, Silver M, van der Zee R, Li T, et al. Isolation of putative progenitor endothelial cells for angiogenesis. Science. 1997;275(5302):964-7 Very important. The article was the first to propose the presence of progenitor endothelial cells and their actvation by ischemia.

44. Tateishi-Yuyama E, Matsubara H, Murohara T, Ikeda U, Shintani $\mathrm{S}$, Masaki $\mathrm{H}$, et al. Therapeutic angiogenesis for patients with limb ischaemia by autologous transplantation of bone-marrow cells: a pilot study and a randomised controlled trial. Lancet. 2002;360(9331):427-35.

45. Iafrati MD, Hallett JW, Geils G, Pearl G, Lumsden A, Peden E, et al. Early results and lessons learned from a multicenter, randomized, double-blind trial of bone marrow aspirate concentrate in critical limb ischemia. J Vasc Surg. 2011;54(6):1650-8.

46. Kajiguchi M, Kondo T, Izawa H, Kobayashi M, Yamamoto K, Shintani S, et al. Safety and efficacy of autologous progenitor cell transplantation for therapeutic angiogenesis in patients with critical limb ischemia. Circ J. 2007;71(2):196-201.

47. Matoba S, Tatsumi T, Murohara T, Imaizumi T, Katsuda Y, Ito M, et al. Long-term clinical outcome after intramuscular implantation of bone marrow mononuclear cells (Therapeutic Angiogenesis by Cell Transplantation [TACT] trial) in patients with chronic limb ischemia. Am Heart J. 2008;156(5):1010-8.

48. Fadini GP, Spinetti G, Santopaolo M, Madeddu P. Impaired regeneration contributes to poor outcomes in diabetic peripheral artery disease. Arterioscler Thromb Vasc Biol. 2020;40(1):3444 Important. The review provides recent information of the cellular and molecular burdens of diabetic vasculopathy.
49. Parikh PP, Liu ZJ, Velazquez OC. A molecular and clinical review of stem cell therapy in critical limb ischemia. Stem Cells Int. 2017;2017:3750829.

50. Madaric J, Valachovicova M, Paulis L, Pribojova J, Mateova R, Sebekova K, et al. Improvement in asymmetric dimethylarginine and oxidative stress in patients with limb salvage after autologous mononuclear stem cell application for critical limb ischemia. Stem Cell Res Ther. 2017;8(1):165.

51. Ohtake T, Mochida Y, Ishioka K, Oka M, Maesato K, Moriya H, et al. Autologous granulocyte colony-stimulating factor-mobilized peripheral blood CD34 positive cell transplantation for hemodialysis patients with critical limb ischemia: a prospective phase II clinical trial. Stem Cells Transl Med. 2018;7(11):774-82.

52. Pignon B, Sevestre MA, Kanagaratnam L, Pernod G, Stephan D, Emmerich J, et al. Autologous bone marrow mononuclear cell implantation and its impact on the outcome of patients with critical limb ischemia- results of a randomized, double-blind, placebocontrolled trial. Circ J. 2017;81(11):1713-20.

53. Molavi B, Zafarghandi MR, Aminizadeh E, Hosseini SE, Mirzayi $\mathrm{H}$, Arab L, et al. Safety and efficacy of repeated bone marrow mononuclear cell therapy in patients with critical limb ischemia in a pilot randomized controlled trial. Arch Iran Med. 2016;19(6): 388-96.

54. Wang SK, Green LA, Motaganahalli RL, Wilson MG, Fajardo A, Murphy MP. Rationale and design of the MarrowStim PAD Kit for the treatment of critical limb ischemia in subjects with severe peripheral arterial disease (MOBILE) trial investigating autologous bone marrow cell therapy for critical limb ischemia. J Vasc Surg. 2017;65(6):1850-7 e2.

55. Velazquez OC. Increasing the therapeutic potential of stem cell therapies for critical limb ischemia. J Stem Cells Res Dev Ther. 2020;6(1):1-7.

56. Pan T, Wei Z, Fang Y, Dong Z, Fu W. Therapeutic efficacy of CD34(+) cell-involved mononuclear cell therapy for no-option critical limb ischemia: a meta-analysis of randomized controlled clinical trials. Vasc Med. 2018;23(3):219-31.

57. Madaric J, Klepanec A, Valachovicova M, Mistrik M, Bucova M, Olejarova I, et al. Characteristics of responders to autologous bone marrow cell therapy for no-option critical limb ischemia. Stem Cell Res Ther. 2016;7(1):116.

58. Gupta PK, Krishna M, Chullikana A, Desai S, Murugesan R, Dutta $\mathrm{S}$, et al. Administration of adult human bone marrow-derived, cultured, pooled, allogeneic mesenchymal stromal cells in critical limb ischemia due to Buerger's disease: phase II study report suggests clinical efficacy. Stem Cells Transl Med. 2017;6(3):689-99.

59. Mathiyalagan P, Liang Y, Kim D, Misener S, Thorne T, Kamide $\mathrm{CE}$, et al. Angiogenic mechanisms of human CD34(+) stem cell exosomes in the repair of ischemic hindlimb. Circ Res. 2017;120(9):1466-76.

60. Sietsema WK, Kawamoto A, Takagi H, Losordo DW. Autologous CD34+ cell therapy for ischemic tissue repair. Circ J. 2019;83(7):1422-30 Important. The paper provides insight into the use of $\mathrm{CD34}+$ cell therapy in ischemia.

61. Barcelos LS, Duplaa C, Krankel N, Graiani G, Invernici G, Katare $\mathrm{R}$, et al. Human CD133+ progenitor cells promote the healing of diabetic ischemic ulcers by paracrine stimulation of angiogenesis and activation of Wnt signaling. Circ Res. 2009;104(9):1095-102 Important. The first study showing molecular insights into the therapeutic application of perivascular progenitor cells in ischemic diabetic ulcers. The authors developped a new model of ulcer and limb ischemia in diabetic mice.

62. Arici V, Perotti C, Fabrizio C, Del Fante C, Ragni F, Alessandrino F, et al. Autologous immuno magnetically selected CD133+ stem cells in the treatment of no-option critical limb ischemia: clinical 
and contrast enhanced ultrasound assessed results in eight patients. J Transl Med. 2015;13:342.

63.•- Armulik A, Genove G, Betsholtz C. Pericytes: developmental, physiological, and pathological perspectives, problems, and promises. Dev Cell. 2011;21(2):193-215 Very important. A fundamental study on the heterogeneous characteristics and therapeutic potential of pericytes.

64.•V Vono R, Fuoco C, Testa S, Pirro S, Maselli D, Ferland McCollough D, et al. Activation of the pro-oxidant PKCbetaIIp66Shc signaling pathway contributes to pericyte dysfunction in skeletal muscles of patients with diabetes with critical limb ischemia. Diabetes. 2016;65(12):3691-704 Very important. A fundamental study on the molecular dificits of pericytes in limb muscles of diabetic patients.

65. D'Souza DM, Al-Sajee D, Hawke TJ. Diabetic myopathy: impact of diabetes mellitus on skeletal muscle progenitor cells. Front Physiol. 2013;4:379.

66. Prazeres P, Turquetti AOM, Azevedo PO, Barreto RSN, Miglino MA, Mintz A, et al. Perivascular cell alphav integrins as a target to treat skeletal muscle fibrosis. Int J Biochem Cell Biol. 2018;99: 109-13.

67. Andre LM, Ausems CRM, Wansink DG, Wieringa B. Abnormalities in skeletal muscle myogenesis, growth, and regeneration in myotonic dystrophy. Front Neurol. 2018;9:368.

68. Campagnolo P, Cesselli D, Al Haj Zen A, Beltrami AP, Krankel N, Katare R, et al. Human adult vena saphena contains perivascular progenitor cells endowed with clonogenic and proangiogenic potential. Circulation. 2010;121(15):1735-45 Important. The first study leading to the derivation of pericytes from human vascular tissue and application in limb ischemia.

69. Gubernator M, Slater SC, Spencer HL, Spiteri I, Sottoriva A, Riu $\mathrm{F}$, et al. Epigenetic profile of human adventitial progenitor cells correlates with therapeutic outcomes in a mouse model of limb ischemia. Arterioscler Thromb Vasc Biol. 2015;35(3):675-88.

70. Campagnolo P, Gormley AJ, Chow LW, Guex AG, Parmar PA, Puetzer JL, et al. Pericyte seeded dual peptide scaffold with improved endothelialization for vascular graft tissue engineering. Adv Healthc Mater. 2016;5(23):3046-55.

71. Faulkner A, Tamiato A, Cathery W, Rampin A, Caravaggi CM, Jover E, et al. Dimethyl-2-oxoglutarate improves redox balance and mitochondrial function in muscle pericytes of individuals with diabetes mellitus. Diabetologia. 2020;63(10):2205-17. Important. The study highlights the possibility of correcting diabetes-related liabilities of muscular pericytes using a metabolite treatment.

72. Hayes KL, Messina LM, Schwartz LM, Yan J, Burnside AS, Witkowski S. Type 2 diabetes impairs the ability of skeletal muscle pericytes to augment postischemic neovascularization in $\mathrm{db} / \mathrm{db}$ mice. Am J Phys Cell Phys. 2018;314(5):C534-C44.

73. Flugelman MY, Halak M, Yoffe B, Schneiderman J, Rubinstein C, Bloom AI, et al. Phase Ib safety, two-dose study of MultiGeneAngio in patients with chronic critical limb ischemia. Mol Ther. 2017;25(3):816-25.

74. Kane NM, Meloni M, Spencer HL, Craig MA, Strehl R, Milligan $\mathrm{G}$, et al. Derivation of endothelial cells from human embryonic stem cells by directed differentiation: analysis of microRNA and angiogenesis in vitro and in vivo. Arterioscler Thromb Vasc Biol. 2010;30(7):1389-97.

75. Huang NF, Niiyama H, Peter C, De A, Natkunam Y, Fleissner F, et al. Embryonic stem cell-derived endothelial cells engraft into the ischemic hindlimb and restore perfusion. Arterioscler Thromb Vasc Biol. 2010;30(5):984-91.

76. Cho SW, Moon SH, Lee SH, Kang SW, Kim J, Lim JM, et al. Improvement of postnatal neovascularization by human embryonic stem cell derived endothelial-like cell transplantation in a mouse model of hindlimb ischemia. Circulation. 2007;116(21):2409-19.

77. Lai WH, Ho JC, Chan YC, Ng JH, Au KW, Wong LY, et al. Attenuation of hind-limb ischemia in mice with endothelial-like cells derived from different sources of human stem cells. PLoS One. 2013;8(3):e57876.

78. MacAskill MG, Saif J, Condie A, Jansen MA, MacGillivray TJ, Tavares AAS, et al. Robust revascularization in models of limb ischemia using a clinically translatable human stem cell-derived endothelial cell product. Mol Ther. 2018;26(7):1669-84.

79. Burgos-Moron E, Abad-Jimenez Z, Maranon AM, Iannantuoni F, Escribano-Lopez I, Lopez-Domenech S, et al. Relationship between oxidative stress, ER stress, and inflammation in type 2 diabetes: the battle continues. J Clin Med. 2019;8(9):1385.

80. Klionsky DJ, Abdelmohsen K, Abe A, Abedin MJ, Abeliovich H, Acevedo Arozena A, et al. Guidelines for the use and interpretation of assays for monitoring autophagy (3rd edition). Autophagy. 2016;12(1):1-222.

81. Bhansali S, Bhansali A, Walia R, Saikia UN, Dhawan V. Alterations in mitochondrial oxidative stress and mitophagy in subjects with prediabetes and type 2 diabetes mellitus. Front Endocrinol (Lausanne). 2017;8:347.

82. Spinetti G, Sangalli E, Tagliabue E, Maselli D, Colpani O, Ferland-McCollough D, et al. microRNA-21/PDCD4 proapoptotic signaling from circulating CD34(+) cells to vascular endothelial cells: a potential contributor to adverse cardiovascular outcomes in patients with critical limb ischemia. Diabetes Care. 2020;43(7):1520-9 Important. The study shows a new model of progenitor cells converted into an adverse phenotype because of oxidative stress in diabetes.

83. Manirujjaman M, Ozaki I, Murata Y, Guo J, Xia J, Nishioka K, et al. Degradation of the tumor suppressor PDCD4 is impaired by the suppression of p62/SQSTM1 and autophagy. Cells. 2020;9(1): 218.

84. Chen J, Song M, Yu S, Gao P, Yu Y, Wang H, et al. Advanced glycation endproducts alter functions and promote apoptosis in endothelial progenitor cells through receptor for advanced glycation endproducts mediate overpression of cell oxidant stress. Mol Cell Biochem. 2010;335(1-2):137-46.

85. Fleissner F, Thum T. Critical role of the nitric oxide/reactive oxygen species balance in endothelial progenitor dysfunction. Antioxid Redox Signal. 2011;15(4):933-48.

86. Hamed S, Brenner B, Aharon A, Daoud D, Roguin A. Nitric oxide and superoxide dismutase modulate endothelial progenitor cell function in type 2 diabetes mellitus. Cardiovasc Diabetol. 2009;8:56

87. Ackah E, Yu J, Zoellner S, Iwakiri Y, Skurk C, Shibata R, et al. Akt1/protein kinase Balpha is critical for ischemic and VEGFmediated angiogenesis. J Clin Invest. 2005;115(8):2119-27.

88. King GL, Park K, Li Q. Selective insulin resistance and the development of ardiovascular diseases in diabetes: the 2015 Edwin Bierman Award Lecture. Diabetes. 2016;65(6):1462-71.

89. Sethi I, Bhat GR, Singh V, Kumar R, Bhanwer AJ, Bamezai RN, et al. Role of telomeres and associated maintenance genes in type 2 diabetes mellitus: a review. Diabetes Res Clin Pract. 2016;122: 92-100.

90. Fadini GP, Sartore S, Schiavon M, Albiero M, Baesso I, Cabrelle A, et al. Diabetes impairs progenitor cell mobilisation after hindlimb ischaemia-reperfusion injury in rats. Diabetologia. 2006;49(12):3075-84.

91. Fadini GP, Agostini C, Avogaro A. Characterization of endothelial progenitor cells. Biochem Biophys Res Commun. 2005;336(1):1-2.

92.• Loomans CJ, de Koning EJ, Staal FJ, Rookmaaker MB, Verseyden C, de Boer HC, et al. Endothelial progenitor cell 
dysfunction: a novel concept in the pathogenesis of vascular complications of type 1 diabetes. Diabetes. 2004;53(1):195-9 Very important. One of the first study identified the dysfunction of progenitor cells in diabetes.

93. Fadini GP, Miorin M, Facco M, Bonamico S, Baesso I, Grego F, et al. Circulating endothelial progenitor cells are reduced in peripheral vascular complications of type 2 diabetes mellitus. J Am Coll Cardiol. 2005;45(9):1449-57.

94. Makino H, Okada S, Nagumo A, Sugisawa T, Miyamoto Y, Kishimoto I, et al. Decreased circulating CD34+ cells are associated with progression of diabetic nephropathy. Diabet Med. 2009;26(2):171-3.

95. Fadini GP, Ciciliot S, Albiero M. Concise review: perspectives and clinical implications of bone marrow and circulating stem cell defects in diabetes. Stem Cells. 2017;35(1):106-16.

96. Amadesi S, Reni C, Katare R, Meloni M, Oikawa A, Beltrami AP, et al. Role for substance p-based nociceptive signaling in progenitor cell activation and angiogenesis during ischemia in mice and in human subjects. Circulation. 2012;125(14):1774-86 S1-19.

97. Dang Z, Maselli D, Spinetti G, Sangalli E, Carnelli F, Rosa F, et al. Sensory neuropathy hampers nociception-mediated bone marrow stem cell release in mice and patients with diabetes. Diabetologia. 2015;58(11):2653-62.

98. Spinetti G, Cordella D, Fortunato O, Sangalli E, Losa S, Gotti A, et al. Global remodeling of the vascular stem cell niche in bone marrow of diabetic patients: implication of the microRNA-155/ FOXO3a signaling pathway. Circ Res. 2013;112(3):510-22.

99. Bonora BM, Cappellari R, Mazzucato M, Rigato M, Grasso M, Menegolo M, et al. Stem cell mobilization with plerixafor and healing of diabetic ischemic wounds: a phase IIa, randomized, double-blind, placebo-controlled trial. Stem Cells Transl Med. 2020;9(9):965-73

100. Warmke N, Griffin KJ, Cubbon RM. Pericytes in diabetesassociated vascular disease. J Diabetes Complicat. 2016;30(8): 1643-50.

101. Cathery W, Faulkner A, Maselli D, Madeddu P. Concise review: the regenerative journey of pericytes toward clinical translation. Stem Cells. 2018;36(9):1295-310.

102. Mangialardi G, Ferland-McCollough D, Maselli D, Santopaolo M, Cordaro A, Spinetti G, et al. Bone marrow pericyte dysfunction in individuals with type 2 diabetes. Diabetologia. 2019;62(7): 1275-90.

103. Mangialardi G, Katare R, Oikawa A, Meloni M, Reni C, Emanueli $\mathrm{C}$, et al. Diabetes causes bone marrow endothelial barrier dysfunction by activation of the RhoA-Rho-associated kinase signaling pathway. Arterioscler Thromb Vasc Biol. 2013;33(3):555-64.

104. Ferland-McCollough D, Maselli D, Spinetti G, Sambataro M, Sullivan N, Blom A, et al. MCP-1 feedback loop between adipocytes and mesenchymal stromal cells causes fat accumulation and contributes to hematopoietic stem cell rarefaction in the bone marrow of patients with diabetes. Diabetes. 2018;67(7):1380-94.

105. Prattichizzo F, Giuliani A, De Nigris V, Pujadas G, Ceka A, La Sala L, et al. Extracellular microRNAs and endothelial hyperglycaemic memory: a therapeutic opportunity. Diabetes Obes Metab. 2016;18(9):855-67.

106. Ceriello A. The emerging challenge in diabetes: the "metabolic memory". Vasc Pharmacol. 2012;57(5-6):133-8.

107. Ceriello A, Esposito K, Piconi L, Ihnat MA, Thorpe JE, Testa R, et al. Oscillating glucose is more deleterious to endothelial function and oxidative stress than mean glucose in normal and type 2 diabetic patients. Diabetes. 2008;57(5):1349-54.

108. Reddy MA, Zhang E, Natarajan R. Epigenetic mechanisms in diabetic complications and metabolic memory. Diabetologia. 2015;58(3):443-55.
109. Zhong X, Liao Y, Chen L, Liu G, Feng Y, Zeng T, et al. The microRNAs in the pathogenesis of metabolic memory. Endocrinology. 2015;156(9):3157-68.

110. Ryu HS, Park SY, Ma D, Zhang J, Lee W. The induction of microRNA targeting IRS-1 is involved in the development of insulin resistance under conditions of mitochondrial dysfunction in hepatocytes. PLoS One. 2011;6(3):e17343.

111. Meng S, Cao JT, Zhang B, Zhou Q, Shen CX, Wang CQ. Downregulation of microRNA-126 in endothelial progenitor cells from diabetes patients, impairs their functional properties, via target gene Spred-1. J Mol Cell Cardiol. 2012;53(1):64-72.

112. Xiao J, Lin HY, Zhu YY, Zhu YP, Chen LW. MiR-126 regulates proliferation and invasion in the bladder cancer BLS cell line by targeting the PIK3R2-mediated PI3K/Akt signaling pathway. Onco Targets Ther. 2016;9:5181-93.

113. Suresh Babu S, Thandavarayan RA, Joladarashi D, Jeyabal P, Krishnamurthy S, Bhimaraj A, et al. MicroRNA-126 overexpression rescues diabetes-induced impairment in efferocytosis of apoptotic cardiomyocytes. Sci Rep. 2016;6:36207.

114. Luan YZL, Zhang S, Wang G, Peng T. MicroRNA-126 acts as a tumor suppressor in glioma cells by targeting insulin receptor substrate 1 (IRS-1). Int J Clin Exp Pathol. 2015;8(9):9.

115.• Spinetti G, Fortunato O, Caporali A, Shantikumar S, Marchetti M, Meloni M, et al. MicroRNA-15a and microRNA-16 impair human circulating proangiogenic cell functions and are increased in the proangiogenic cells and serum of patients with critical limb ischemia. Circ Res. 2013;112(2):335-46 Important. One of the first study to show the contribution of microRNAs in progenitor cells dysfunction associated with diabetes.

116. Slater SC, Jover E, Martello A, Mitic T, Rodriguez-Arabaolaza I, Vono R, et al. MicroRNA-532-5p regulates pericyte function by targeting the transcription regulator BACH1 and angiopoietin-1. Mol Ther. 2018;26(12):2823-37.

117. Deiuliis JA. MicroRNAs as regulators of metabolic disease: pathophysiologic significance and emerging role as biomarkers and therapeutics. Int J Obes. 2016;40(1):88-101.

118. Mensa E, Giuliani A, Matacchione G, Gurau F, Bonfigli AR, Romagnoli $\mathrm{F}$, et al. Circulating miR-146a in healthy aging and type 2 diabetes: age- and gender-specific trajectories. Mech Ageing Dev. 2019;180:1-10.

119. Meng S, Cao J, Zhang X, Fan Y, Fang L, Wang C, et al. Downregulation of microRNA-130a contributes to endothelial progenitor cell dysfunction in diabetic patients via its target Runx3. PLoS One. 2013;8(7):e68611.

120. Olivieri F, Spazzafumo L, Bonafe M, Recchioni R, Prattichizzo F, Marcheselli F, et al. MiR-21-5p and miR-126a-3p levels in plasma and circulating angiogenic cells: relationship with type 2 diabetes complications. Oncotarget. 2015;6(34):35372-82.

121. Cheng B, Li JY, Li XC, Wang XF, Wang ZJ, Liu J, et al. MiR$323 b-5 p$ acts as a novel diagnostic biomarker for critical limb ischemia in type 2 diabetic patients. Sci Rep. 2018;8(1):15080.

122. Li JY, Cheng B, Wang XF, Wang ZJ, Zhang HM, Liu SF, et al. Circulating microRNA-4739 may be a potential biomarker of critical limb ischemia in patients with diabetes. Biomed Res Int. 2018;2018:4232794.

123. Cheng S, Cui Y, Fan L, Mu X, Hua Y. T2DM inhibition of endothelial miR-342-3p facilitates angiogenic dysfunction via repression of FGF11 signaling. Biochem Biophys Res Commun. 2018;503(1):71-8.

124. Widlansky ME, Jensen DM, Wang J, Liu Y, Geurts AM, Kriegel AJ, et al. miR-29 contributes to normal endothelial function and can restore it in cardiometabolic disorders. EMBO Mol Med. 2018;10(3):e8046.

125. Yuan J, Chen M, Xu Q, Liang J, Chen R, Xiao Y, et al. Effect of the diabetic environment on the expression of MiRNAs in endothelial cells: Mir-149-5p restoration ameliorates the high glucose- 
induced expression of TNF-alpha and ER stress markers. Cell Physiol Biochem. 2017;43(1):120-35.

126. He X, Du C, Zou Y, Long Y, Huang C, Chen F, et al. Downregulation of MicroRNA-4463 attenuates high-glucoseand hypoxia-induced endothelial cell injury by targeting PNUTS. Cell Physiol Biochem. 2018;49(5):2073-87.

127. Blum A, Meerson A, Rohana H, Jabaly H, Nahul N, Celesh D, et al. MicroRNA-423 may regulate diabetic vasculopathy. Clin Exp Med. 2019;19(4):469-77.

128. Wang H, Wang Z, Tang Q. Reduced expression of microRNA$199 a-3 p$ is associated with vascular endothelial cell injury induced by type 2 diabetes mellitus. Exp Ther Med. 2018;16(4):3639-45.

129. Zou HL, Wang Y, Gang Q, Zhang Y, Sun Y. Plasma level of miR93 is associated with higher risk to develop type 2 diabetic retinopathy. Graefes Arch Clin Exp Ophthalmol. 2017;255(6):115966.

130. Amin KN, Umapathy D, Anandharaj A, Ravichandran J, Sasikumar CS, Chandra SKR, et al. miR-23c regulates wound healing by targeting stromal cell-derived factor-1alpha (SDF-1alpha/CXCL12) among patients with diabetic foot ulcer. Microvasc Res. 2020;127:103924.

131. Zhang Y, Guan Q, Jin X. Platelet-derived miR-92a downregulates cysteine protease inhibitor cystatin $\mathrm{C}$ in type II diabetic lower limb ischemia. Exp Ther Med. 2015;9(6):2257-62.

132. Zhang HN, Xu QQ, Thakur A, Alfred MO, Chakraborty M, Ghosh A, et al. Endothelial dysfunction in diabetes and hypertension: role of microRNAs and long non-coding RNAs. Life Sci. 2018;213:258-68.

133. Puthanveetil P, Chen S, Feng B, Gautam A, Chakrabarti S. Long non-coding RNA MALAT1 regulates hyperglycaemia induced inflammatory process in the endothelial cells. J Cell Mol Med. 2015;19(6):1418-25.

134. Liu JY, Yao J, Li XM, Song YC, Wang XQ, Li YJ, et al. Pathogenic role of IncRNA-MALAT1 in endothelial cell dysfunction in diabetes mellitus. Cell Death Dis. 2014;5:e1506.

135. Qiu GZ, Tian W, Fu HT, Li CP, Liu B. Long noncoding RNAMEG3 is involved in diabetes mellitus-related microvascular dysfunction. Biochem Biophys Res Commun. 2016;471(1):135-41.

136. Lasda E, Parker R. Circular RNAs: diversity of form and function. RNA. 2014;20(12):1829-42.
137. Ebbesen KK, Kjems J, Hansen TB. Circular RNAs: identification, biogenesis and function. Biochim Biophys Acta. 2016;1859(1): $163-8$.

138. Salzman J. Circular RNA expression: its potential regulation and function. Trends Genet. 2016;32(5):309-16.

139. Liu C, Ge HM, Liu BH, Dong R, Shan K, Chen X, et al. Targeting pericyte-endothelial cell crosstalk by circular RNA-cPWWP2A inhibition aggravates diabetes-induced microvascular dysfunction. Proc Natl Acad Sci U S A. 2019;116(15):7455-64.

140. Pan L, Lian W, Zhang X, Han S, Cao C, Li X, et al. Human circular RNA0054633 regulates high glucoseinduced vascular endothelial cell dysfunction through the microRNA218/roundabout 1 and microRNA218/heme oxygenase1 axes. Int J Mol Med. 2018;42(1):597-606.

141. Shan K, Liu C, Liu BH, Chen X, Dong R, Liu X, et al. Circular noncoding RNA HIPK3 mediates retinal vascular dysfunction in diabetes mellitus. Circulation. 2017;136(17):1629-42.

142. Liu C, Yao MD, Li CP, Shan K, Yang H, Wang JJ, et al. Silencing of circular RNA-ZNF609 ameliorates vascular endothelial dysfunction. Theranostics. 2017;7(11):2863-77.

143. Cheng J, Liu Q, Hu N, Zheng F, Zhang X, Ni Y, et al. Downregulation of hsa_circ_0068087 ameliorates TLR4/NFkappaB/NLRP3 inflammasome-mediated inflammation and endothelial cell dysfunction in high glucose conditioned by sponging miR-197. Gene. 2019;709:1-7.

144. Yang F, Chen Y, Xue Z, Lv Y, Shen L, Li K, et al. Highthroughput sequencing and exploration of the lncRNAcircRNA-miRNA-mRNA network in type 2 diabetes mellitus. Biomed Res Int. 2020;2020:8162524.

145. Zhao W, Liang J, Chen Z, Diao Y, Miao G. Combined analysis of circular RNA and micro RNA profiles and interactions in patients with diabetic foot and diabetes mellitus. Int Wound J. 2020;17(5): 1183-93.

146. Pan T, Liu H, Fang Y, Wei Z, Gu S, Fang G, et al. Predictors of responders to mononuclear stem cell-based therapeutic angiogenesis for no-option critical limb ischemia. Stem Cell Res Ther. 2019;10(1):15.

Publisher's Note Springer Nature remains neutral with regard to jurisdictional claims in published maps and institutional affiliations. 